\title{
Study of the Impact of Environmental Pollution on Efficiency and Sustainable Development using Data Envelopment Analysis
}

\author{
${ }^{1}$ Hamid Hosseini, ${ }^{2}$ Sara Fanati Rashidi ${ }^{*}$ and ${ }^{3}$ Ali Hamzehee \\ ${ }^{1,3}$ Department of Mathematics, Kerman Branch \\ Islamic Azad University, Kerman, Iran \\ ${ }^{2}$ Department of Mathematics, Shiraz Branch \\ Islamic Azad University, Shiraz, Iran \\ ${ }^{*}$ Corresponding author: sarafanati@yahoo.com
}

Article history

Received: 8 July 2019

Received in revised form: 13 July 2020

Accepted: 15 July 2020

Published online: 1 August 2020

\begin{abstract}
Environmental changes resulting from industrial activity have been occurring for many years, and with the increasing production of greenhouse gases and other pollutants, these changes have played a critical role in global warming. Nowadays, all countries have become aware of the great importance of attention to the environment alongside economic growth. Therefore, they are all after solutions that would allow maximum economic growth with minimum harm to the environment. In the present study, the environmental efficiency of a given system is evaluated using data envelopment analysis (DEA). For this purpose, the economic and environmental dimensions are taken into consideration for each decision-making unit (DMU), with the condition of having undesirable outputs in the environmental dimension. Then, using the concept of "order of efficiency", an enhanced DEA method is proposed based on weak and strong disposability axioms, which can be used to compare and rank units with undesirable outputs. Next, the capabilities of the proposed approach are demonstrated through an example involving various industries in Iran. Enhanced DEA not only takes more comprehensive input and output sets into account but also monitors the units based on the principles of sustainability.
\end{abstract}

Keywords Data envelopment analysis; desirable and undesirable outputs; efficiency sustainability; environmental efficiency.

Mathematics Subject Classification 90C90

\section{Introduction}

Nowadays, environmental issues, as one of the main components of sustainable development, have become a concern for international organizations, scholars, and scientific and research centers all over the world. Thereby, it is crucial to raise public awareness about the importance 
of environmental problems in sustainable development. Hence, proper education is one of the most significant cornerstones for sustainable development in terms of human resources, which plays a fundamental role in a balanced economic, environmental, and social development [1]. Sustainable development not only tries to improve and expand the lives of the current generation but also focuses on protecting the future generations, and on that basis, it takes the human conditions and the environmental situation into account simultaneously.

Sustainable development integrates the economic, social, and environmental goals of the society, whenever possible, by policy making, taking the necessary measures, and taking supportive action, and whenever not possible, by establishing an exchange relationship between them and studying and coordinating the exchanges [2].

The triple dimensions of development include: the social dimension, which is concerned with human relationships, welfare promotion, and increased access to healthcare and educational services; the economic dimension, which focuses on the welfare of society and individuals; and the environmental dimension, which is related to the preservation and reinforcement of physical and biological resources and the ecosystem, as well as the human-nature relationship [3].

Currently, humans' resource utilization rate is higher than the biocapacity of the Earth. In this regard, for each year that humans live on the Earth, a year and a half is required to replenish the resources. Development should be in line with nature's laws, as no amount of progress and technological advancement can compare to nature and disturbing the cycle of nature would result in a lot of harm to human lives [4].

It is cause for much hope that in the last few years, the planners and executive authorities have paid special attention to this critical area, which is itself resulted by the increased level of public awareness on the matter. However, there is still a long way to go in order to reach the desirable state, and with the appropriate substrates in place, we hope to one day achieve this ideal situation [5]. The majority of sustainability evaluation methods only outline a path to the target [6], as there are no quantitative guidelines for increasing the level of sustainability. Meanwhile, mathematical programming can be incorporated into the quantitative methods in order to improve their environmental performance [7].

Data envelopment analysis (DEA) is a linear programming method initially proposed by Charnes [8] in 1978. In this method, a linear programming model called CCR was presented for evaluating the efficiency of decision-making units with multiple inputs and multiple outputs. In an objective evaluation of DMUs, there is a problem relating the undesirable outputs formed alongside the desirable ones. Traditional DEA studies only value the desirable outputs and simply disregard the undesirable outputs. In the meantime, to ignore the undesirable outputs is to say that they have no value in the final evaluation, which could lead to misleading results. Therefore, the decision-making units (DMUs) should receive points for their desirable output production and lose points for their undesirable outputs. One of the problems with DEA was the negligence of undesirable outputs in its mathematical models.

Later on, Pittman [9] engaged in justifying the economic costs of undesirable outputs using shadow prices, and following that, the work by Fare [10] can be considered as one of the most pivotal studies relating undesirable outputs. In recent years, several studies were conducted with a focus on evaluating the environmental efficiency of various systems $[11,12,13,14,15$, $16,17]$. There were also a number of studies using DEA to evaluate environmental, social, and economic indicators [18, 19, 20, 21]. Furthermore, Galán-Martín et al. [22] studied the sustainability efficiency of systems based on environmental, social, and economic indicators 
using the concept of "order of efficiency". But their work also has some shortcomings, such as the fact that the data are optimally selected, and in reality, it is rarely possible to find a product that does not produce pollutants. In addition, a limited problem with only one output has been investigated with all values equal to one.

Increasing the discrimination power in standard DEA without loss to information is a great challenge that has attracted a lot of research interest. In this respect, various approaches have been proposed to resolve the problem of DMU ranking in DEA [23, 24].

One of the important methods of DMU ranking is based on cross efficiency [25, 26, 27], where the units are evaluated by themselves or by other DMUs. Moreover, some authors have used super efficiency methods in this context [28, 29]. Some proposed methods involved finding common weights to obtain the optimal solutions, which were then used to discriminate between the units [30, 31]. Benchmarking and statistical techniques are also some of the methods used for DMU ranking [32, 33]. Additionally, some researchers combined DEA with multi-criteria decision-making methods for this purpose [34, 35]. However, despite the large number of approaches presented for DMU discrimination in DEA, no one method alone is considered a complete solution to this ranking problem.

\section{Background of DEA}

In this section, we first present the basic principles of a standard DEA, and then, describe the DEA models for desirable and undesirable data. The concepts of order of efficiency and sustainability will be described in the next sections.

\subsection{Standard Data Envelopment Analysis}

Given that our objective in this research is to measure efficiency in economic and environmental dimensions in different orders, the following linear programming problem is used to obtain the efficiency of units that only include desirable data. Assume that $D M U_{j}(j=1,2, \ldots, n)$ produces $n$ congruent decision-making units using the input vector $X_{j} \in \mathbb{R}^{m}(j=1,2, \ldots, n)$ and the output vector $Y_{j} \in \mathbb{R}^{s}(j=1,2, \ldots, n)$, meaning that vector $X_{j}$ has $m$ components and vector $Y_{j}$ has $s$ components [8].

$\operatorname{Max} \varphi$ such that

$$
\begin{aligned}
& \sum_{j=1}^{n} \lambda_{j} X_{j} \leq X_{0}, \\
& \sum_{j=1}^{n} \lambda_{j} Y_{j} \geq \varphi Y_{0}, \\
& \lambda_{j} \geq 0, j=1,2,3, \cdots, n,
\end{aligned}
$$

where $\varphi$ is the efficiency of the under evaluation Decision Making Unit that is shown by $D M U_{o}$. $\lambda_{j}$ are the variables of the aforementioned model that are non-negative linear combination of $D M U_{j} s(\mathrm{j}=1, \ldots, \mathrm{n}) . D M U_{j} s$ are observed decision making units.

As previously mentioned, the environmental aspect of decision-making units is a significant dimension of efficiency evaluation in this research, which has recently become a subject of 
interest for senior managers. In actuality, global economy is inextricably linked with the environment, as it is dependent on the extraction and exploitation of natural resources. Nowadays, it is becoming a widely accepted opinion that without taking into account the pollution, waste, and dangers that economic activities and the production-consumption cycle impose on the environment and eventually the humans themselves, economic growth will not be sustainable. The fact is, alongside their useful products, DMUs often enter an amount of pollution and waste into the environment, which are known as undesirable outputs in DEA [10].

\subsection{Axioms Holding for Undesirable Outputs}

The axioms that hold for undesirable outputs are defined as follows

The standard production possibility set (PPS) is defined as follows:

$$
\operatorname{PPS}=\left\{(\mathbf{X}, \mathbf{Y}) \mid \mathbf{X} \geq \sum_{j=1}^{n} \lambda_{j} \mathbf{X}_{\mathbf{j}}, \mathbf{Y} \leq \sum_{J=1}^{n} \lambda_{j} \mathbf{Y}_{\mathbf{j}}, \lambda_{j} \geq 0, j=1,2, \ldots, n\right\} .
$$

\subsubsection{Null-joint Property}

We have the following properties based on the principles of undesirable outputs.

Undesirable outputs are null-joint when

$$
\left(\mathbf{Y}^{D}, \mathbf{Y}^{U}\right) \in P P S, \quad \mathbf{Y}^{U}=0 \rightarrow \mathbf{Y}^{D}=0
$$

where $\mathbf{Y}^{D}$ denotes the desirable output vector and $\mathbf{Y}^{U}$ is the undesirable output vector. In other words if an output vector $\left(\mathbf{Y}^{D}, \mathbf{Y}^{U}\right)$ is feasible and there are no bad outputs produced then under null jointness only zero good output can be produced. Equivalently if some positive amount of the good output is produced then some bad output must also be produced [36]. The condition of null-joint was introduced by Shephard and Färe [37] and has been discussed for environmental problems by Färe and Grosskopf [36] and Shephard and Färe [37]. This axiom shows that if the desirable outputs have positive values, the undesirable outputs will definitely have positive values as well. For instance, it would not be possible to produce paper without producing an amount of sulfur [36].

\subsubsection{Weak Disposability}

In most processes, undesirable outputs are produced alongside the desirable ones. This axiom states that by reducing the amount of desirable outputs, undesirable outputs will be reduced as well [36]. In other words, according to the axiom, reducing the desirable outputs by a certain ratio would require the reduction of undesirable outputs by that same ratio. Thereby, based on the weak disposability axiom and the standard production set, a new production possibility set (PPS) is denoted by $P^{W}(\mathbf{X})$ and defined as follows.

$$
P^{W}(\mathbf{X})=\left\{\left(\mathbf{X},\left(\begin{array}{c}
\mathbf{Y}^{D K} \\
\mathbf{Y}^{U K}
\end{array}\right)\right) \mid \mathbf{Y}^{D K} \leq \mathbf{Y}^{D} \lambda, \mathbf{Y}^{U K}=\mathbf{Y}^{U} \lambda, \mathbf{X} \lambda \leq \mathbf{X}, \lambda \in \mathbb{R}_{+}^{n}\right\},
$$

where $\mathbf{Y}^{D K}$ is desirable output and $\mathbf{Y}^{U K}$ is undesirable output of $D M U_{k}$. 
In the following, Model (2) shows the linear programming form of the PPS [36]. Note that $j=1,2, \ldots, n$ is the number of $D M U_{\mathrm{S}}$ that consume the input vector $\mathbf{X} \in \mathrm{R}^{m}$ to produce the desirable output vector $\mathbf{Y} \in \mathrm{R}^{s}$ and the undesirable output vector $\mathbf{U} \in \mathrm{R}^{+}$.

$\operatorname{Max} \varphi_{0}$ such that

$$
\begin{aligned}
& \sum_{j=1}^{n} \lambda_{j} X_{j} \leq X_{0}, \\
& \sum_{j=1}^{n} \lambda_{j} Y_{j} \geq \varphi_{0} Y_{o}, \\
& \sum_{j=1}^{n} \lambda_{j} U_{j}=U_{o}, \\
& \lambda_{j} \geq 0, j=1,2, \ldots, n,
\end{aligned}
$$

where $\varphi_{o}$ is the efficiency of the under evaluation Decision Making Unit that is shown by $D M U_{o}$. $\lambda_{j}$ are the variables of the aforementioned model that are non-negative linear combination of $D M U_{j} s(\mathrm{j}=1, \ldots, \mathrm{n})$. $D M U_{j}$ are observed decision making units.

\subsubsection{Strong Disposability}

This axiom imposes certain conditions on the model and states that it is possible to increase the desirable outputs while preventing the same amount of increase in the undesirable outputs; in some cases, undesirable output production can be even reduced down to the lowest amount possible [39].

Based on the strong disposability axiom, the production possibility set is given by

$$
P^{S}(\mathbf{X})=\left\{\left(\mathbf{X} .\left(\begin{array}{c}
\mathbf{Y}^{D K} \\
\mathbf{Y}^{U K}
\end{array}\right)\right) \mid \mathbf{Y}^{D K} \leq \mathbf{Y}^{D} \lambda, \mathbf{Y}^{U K} \leq \mathbf{Y}^{U} \lambda, \mathbf{X} \lambda \leq \mathbf{X}^{K}, 1 \lambda=1, \lambda \in \mathbb{R}_{+}^{n}\right\}
$$

Model (3) presents the nonlinear programming problem for this PPS, where there are $n$ decisionmaking units with the input vector $\mathbf{X} \in \mathrm{R}^{m}$, the desirable output vector $\mathbf{Y} \in \mathrm{R}^{s}$, and the undesirable output vector $\mathbf{U} \in \mathbb{R}^{+}, \mathbf{X}^{K}, \mathbf{Y}^{D K}, \mathbf{Y}^{U K}$ are input, desirable output, undesirable output of under evaluation DMU, respectively [39, 40, 41].

Undoubtedly, in order to improve the performance, the desirable outputs should be increased while the undesirable outputs are reduced. To increase the desirable outputs and reduce the undesirable ones, the following nonlinear programming model is used [10, 39, 40,41,42].

$\operatorname{Max} \varphi_{o}$ such that

$$
\begin{aligned}
& \sum_{j=1}^{n} \lambda_{j} X_{j} \leq X_{o}, \\
& \sum_{j=1}^{n} \lambda_{j} Y_{j} \geq \varphi_{o} Y_{o}, \\
& \sum_{j=1}^{n} \lambda_{j} U_{j} \geq \frac{1}{\varphi_{o}} U_{o},
\end{aligned}
$$




$$
\begin{aligned}
& \sum_{j=1}^{n} \lambda_{j}=1, \\
& \lambda_{j} \geq 0, j=1,2, \ldots, n,
\end{aligned}
$$

where $\varphi_{o}$ is the efficiency of $D M U_{o} . \lambda_{j}$ are the variables of the aforementioned model that are non-negative linear combination of $D M U_{j}(j=1, \ldots, n) . \mathbf{U}_{\mathbf{j}}$ are undesirable outputs of $D M U_{j}$ and $\mathbf{U}_{\mathbf{o}}$ is undesirable output of $D M U_{o}$.

\section{Sustainability Evaluation}

The majority of the existing research on data envelopment analysis are based on economic efficiency. However, since global economy and efficiency evaluation are influenced by ecological (the environment), social, and economic components, environmental factors such as pollution and social challenges and harms such as cultural changes, labor strikes, etc., have an impact on efficiency. To meet the abovementioned need, in this study, efficiency is evaluated in each sustainability dimension (economic, environmental, and social) separately, and the results are added together to arrive at the overall sustainability efficiency. Therefore, a given decisionmaking unit will have a sustainability efficiency score of one if it is deemed efficient in all three dimensions. Assume that $\varphi_{j}^{d}$ is the efficiency score of $D M U_{j}$ in the sustainability dimensiond, i.e., the efficiency score calculated by DEA when only the inputs of this dimension are taken into account. In this respect, the overall sustainability efficiency is defined as the mean of efficiency scores in every sustainability dimension, which is denoted by $\varphi_{j}^{\text {sust }}$ and calculated by the formula

$$
\varphi_{j}^{s u s t}=\frac{\sum_{d \in D} \varphi_{j}^{d}}{|D|} \forall_{j} \in J(4) .
$$

It is worth mentioning that $D$ is the sustainability dimension and the efficiency scores $\varphi_{j}^{d}$ and $\varphi_{j}^{\text {sust }}$ fall within the interval $[0,1]$. The higher the efficiency score of a sustainability dimension, the higher its level of efficiency. If the overall sustainability efficiency score was equal to one $\left(\varphi_{j}^{\text {sust }}=1\right)$, it would indicate that the unit is efficient in all three sustainability dimensions.

\section{Order of Efficiency}

This section will introduce the concept of "order of efficiency" as presented by Das in 1999. In this approach, we are dealing with variations of the problem [43].

Definition 1 A solution is said to be efficient of order if it is not dominated by any other solution in any possible subset of objectives with elements.

After integrating this approach into the concept of data envelopment analysis, the following definition is proposed.

Definition $2 D M U_{0}$ will be efficient if and only if it is deemed efficient in any possible subset of inputs and outputs with $k$ elements. 
From a computational perspective, the previous definition means that we repeat the DEA models iteratively for all possible combinations of inputs and outputs.

Since the present research puts an emphasis on environmental indicators, DEA models for undesirable outputs are used to calculate the orders of efficiency and the undesirable output combinations.

\section{Efficiency Calculation Algorithm Based on Economic, Environ- mental, and Social Indicators}

If we assume $J$ to be a set of decision-making units, $j=1,2,3, \ldots,|J|$, while $T$ is the set of sustainability indicators in each dimension, we will have the following steps.

Step 1: Categorization of indicators (inputs or outputs) in each sustainability dimension. For example, $I_{d}$ represents all the inputs related to dimension $d$ and $O_{d}$ denotes all the outputs related to dimension $d$.

Step 2: All possible combinations of inputs and outputs $(t)$ are identified in every sustainability dimension, in a way that each include $k$ inputs from $\left|I_{d}\right|$ and $k$ outputs from $\left|O_{d}\right|$, and maximum possible combinations are obtained through $\left(\begin{array}{c}I_{d} \\ k\end{array}\right)$ for the inputs and $\left(\begin{array}{c}O_{d} \\ k\end{array}\right)$ for the outputs.

Step 3: The DEA model, denoted by $\varphi_{j k t}^{d}$, is solved for each $D M U_{j}$ in each output combination $t_{k}$ in order to identify the efficient units. Note that $T_{k d}$ is the set of combinations of order in dimension $d$ and $K_{d}$ represents the set of allowable indicators in dimension $d$.

Step 4: Efficiency of order $k$ is determined for each $D M U_{j}$ using the formula

$$
\varphi_{j k}^{d}=\frac{\sum_{t \in T_{k d}} \varphi_{j k t}^{d}}{\left(\begin{array}{c}
\left|O_{d}\right| \\
k
\end{array}\right)}, \forall d \in D \cdot j \in J . k \in K_{d} .
$$

Step 5: We define an overall efficiency score for each $D M U_{j}$ in every dimension, which is technically the mean of efficiency scores obtained for all orders of efficiency and is denoted by $\varphi_{j}^{d}$ :

$$
\varphi_{j}^{d}=\frac{\sum_{k \in K_{d}} \sum_{t \in T_{k d}} \varphi_{j k t}^{d}}{\sum_{t \in K_{d}}\left(\begin{array}{c}
\left|O_{d}\right| \\
k
\end{array}\right)}, \forall d \in D, j \in J
$$

Step 6: Finally, having obtained the efficiency scores in all dimensions, we can determine the overall sustainability efficiency through the formula

$$
\varphi_{j}^{\text {sust }}=\frac{\sum_{d \in D} \varphi_{j}^{d}}{|D|}, \forall j \in J .
$$




\section{Case Study}

In this section, we aim to study and evaluate the efficiency of 17 different industries in Iran, which are considered as our decision-making units. Each DMU has three inputs, two desirable outputs, and three undesirable outputs (environmental pollutants), which are classified into the economic, environmental, and social dimensions. Note that by pollutants in this article, we are referring to the $\mathrm{CO}_{2}$ (carbon dioxide), SPM (suspended particulate matter), and $\mathrm{SO}_{2}$ (sulfur dioxide) resulting from the use of fossil fuels, which was first studied in Iranian manufacturing industries from an environmental aspect by [44]. Note that the values extracted for the inputs and the desirable and undesirable outputs of the 17 industries under study are calculated as percentages within the same period of time. In addition, the undesirable outputs, including $\mathrm{CO}_{2}$, SPM, and $\mathrm{SO}_{2}$, are calculated in tons, the employee counts are specified in terms of million individuals, and value added, import turnover, and export turnover are calculated in billion Riyal. In the current study, the efficiency of these industries is evaluated based on economic and environmental indicators using the proposed models. In this respect, capital, number of employees, and import turnover are the inputs in the economic dimension denoted by $I_{1}, I_{2}$ and $I_{3}$, respectively, value added and export turnover are the desirable outputs denoted by $O_{1}$ and $\mathrm{O}_{2}$, respectively, and the three environmental pollutants under study are our undesirable outputs denoted by $\mathrm{O}_{3}, \mathrm{O}_{4}$ and $\mathrm{O}_{5}$, respectively. Based on Model (3), in efficiency of order 1 , the three inputs and the two desirable outputs are kept fixed while the undesirable outputs $\left\{O_{3}\right\},\left\{O_{4}\right\}$, and $\left\{O_{5}\right\}$ are substituted in three configurations. In efficiency of order 2 , the three inputs and the two desirable outputs are kept fixed and the undesirable output combinations $\left\{\mathrm{O}_{3}, \mathrm{O}_{4}\right\},\left\{\mathrm{O}_{3}, \mathrm{O}_{5}\right\}$, and $\left\{\mathrm{O}_{4}, \mathrm{O}_{5}\right\}$ are substituted in three configurations. Finally, in efficiency of order 3, while keeping the three inputs and the two desirable outputs fixed, a combination of all three undesirable outputs is taken into consideration, namely $\left\{\mathrm{O}_{3}, \mathrm{O}_{4}, \mathrm{O}_{5}\right\}$. Table 1 presents the data used for the 17 Iranian industries in this study.

After solving Model (1) for the economic efficiency (desirable data) and Model (3) for the environmental efficiency (undesirable data) for 17 DMUs, using General Algebraic Modeling System (GAMS), the efficiency scores based on economic and environmental indicators were obtained. The results of economic efficiency, environmental efficiency, the efficiency of various orders, and overall efficiency are presented are presented in Tables 2 to 5 respectively.

Step 1: We consider the economic and environmental dimensions as $d=1$ (value added and import turnover) and $d=2\left(\mathrm{CO}_{2}, \mathrm{SPM}\right.$, and $\left.\mathrm{SO}_{2}\right)$, respectively. Therefore, $\mathrm{O}_{1}=|2|$ represents all desirable outputs in the economic dimension and $\mathrm{O}_{2}=|3|$ stands for all environmentally undesirable outputs.

Step 2: All possible combinations of desirable outputs are defined as $O_{1}$, while $O_{2}$ represents all possible combinations of environmentally undesirable outputs. In this respect,

$$
\begin{aligned}
& O_{1}=\left\{\left\{O_{1}\right\},\left\{O_{2}\right\},\left\{O_{1}, O_{2}\right\}\right\}, \\
& O_{2}=\left\{\left\{O_{3}\right\},\left\{O_{4}\right\},\left\{O_{5}\right\},\left\{O_{3}, O_{4}\right\},\left\{O_{3}, O_{5}\right\},\left\{O_{4}, O_{5}\right\},\left\{O_{3}, O_{4}, O_{5}\right\}\right\} .
\end{aligned}
$$

Step 3: The DEA model is solved for each DMU and for each output combination $t_{k}$. The models are denoted by $\varphi_{j 11}^{1}$ and $\varphi_{j 12}^{1}$ in order 1 and $\varphi_{j 21}^{1}$ in order 2 . Now, we form a set of order combinations of order $k$ in dimension $d$ as follows:

$T_{11}=\left\{\left\{O_{11}\right\},\left\{O_{12}\right\}\right\}$ for efficiency of order 1 , where $t=2$, and $T_{21}=\left\{\left\{O_{11}\right\},\left\{O_{12}\right\}\right\}$ for efficiency of order 2 , where $t=1$. 
Table 1: Desirable and Undesirable Inputs and Outputs in the 17 Iranian Industries under Study

\begin{tabular}{|c|l|c|c|c|c|c|c|c|c|}
\hline Code & Industry & $\boldsymbol{I}_{1}$ & $\boldsymbol{I}_{2}$ & $\boldsymbol{I}_{3}$ & $\boldsymbol{O}_{1}$ & $\boldsymbol{O}_{2}$ & $\boldsymbol{O}_{3}$ & $\boldsymbol{O}_{4}$ & $\boldsymbol{O}_{5}$ \\
\hline 1 & Food & 10.05 & 15.41 & 13.97 & 8.34 & 9.26 & 37.75 & 11.47 & 16.00 \\
\hline 2 & $\begin{array}{l}\text { Textiles \& } \\
\text { Clothing }\end{array}$ & 4.60 & 9.93 & 1.70 & 3.85 & 2.78 & 8.07 & 2.51 & 3.88 \\
\hline 3 & Leather & 0.16 & 0.85 & 0.02 & 0.32 & 0.36 & 0.53 & 0.13 & 0.26 \\
\hline 4 & Wood & 0.36 & 0.67 & 0.04 & 0.36 & 0.04 & 1.27 & 0.39 & 0.62 \\
\hline 5 & Paper & 0.88 & 1.63 & 3.21 & 0.83 & 0.10 & 0.22 & 1.10 & 1.30 \\
\hline 6 & \begin{tabular}{l} 
Publishing \\
\hline 7
\end{tabular} & 0.37 & 1.19 & 0.07 & 0.47 & 0.04 & 0.10 & 0.01 & 0.09 \\
\hline 8 & Coal & 4.01 & 1.46 & 0.89 & 11.19 & 25.11 & 13.79 & 13.20 & 10.25 \\
\hline 9 & Plastics & 3.15 & 4.71 & 3.79 & 2.70 & 2.68 & 1.93 & 0.93 & 1.15 \\
\hline 10 & Minerals & 10.51 & 14.37 & 1.02 & 8.63 & 3.85 & 13.22 & 39.60 & 49.94 \\
\hline 11 & Metals & 16.54 & 6.44 & 10.04 & 17.00 & 12.40 & 7.79 & 15.10 & 1.07 \\
\hline 12 & $\begin{array}{l}\text { Fabricated } \\
\text { Metal Products }\end{array}$ & 1.92 & 6.50 & 2.45 & 3.27 & 1.57 & 0.27 & 1.15 & 1.63 \\
\hline 13 & Machinery & 5.21 & 12.57 & 34.49 & 7.24 & 3.40 & 3.61 & 0.72 & 2.42 \\
\hline 14 & $\begin{array}{l}\text { Radio \& } \\
\text { Manufacturing }\end{array}$ & 0.35 & 0.81 & 1.60 & 0.51 & 0.46 & 0.01 & 0.05 & 0.05 \\
\hline 15 & $\begin{array}{l}\text { Medical } \\
\text { Instrumentation }\end{array}$ & 0.26 & 1.04 & 2.50 & 0.45 & 0.04 & 0.30 & 0.11 & 0.17 \\
\hline $\begin{array}{l}\text { Andomotive } \\
\text { Murniture }\end{array}$ & 7.06 & 13.65 & 3.48 & 19.38 & 0.67 & 2.96 & 1.38 & 1.92 \\
\hline 17 & 1.01 & 1.64 & 0.50 & 0.61 & 0.18 & 0.64 & 0.25 & 0.36 \\
\hline
\end{tabular}


Similar to the previous case, in the environmental dimension: $\varphi_{j 1 t}^{2}$ is efficiency of order $1, \varphi_{j 2 t}^{2}$ denotes efficiency of order 2 , and $\varphi_{j 3 t}^{2}$ represents efficiency of order 3 . Moreover, a set of combinations of order $k$ in the environmental dimension is as follows:

$$
\begin{aligned}
& T_{12}=\left\{\left\{O_{3}\right\},\left\{O_{4}\right\},\left\{O_{5}\right\}\right\} \text { for efficiency of order } 1 \text {, where } t=3, \\
& T_{22}=\left\{\left\{O_{3}, O_{4}\right\},\left\{O_{3}, O_{5}\right\},\left\{O_{4}, O_{5}\right\}\right\} \text { for efficiency of order } 2, \text { where } t=3, \text { and } \\
& T_{32}=\left\{\left\{O_{3}, O_{4}, O_{5}\right\}\right\} \text { for efficiency of order } 3, \text { where } t=1 .
\end{aligned}
$$

Step 4: We determine the efficiency of order $k$ for each $D M U_{j}$ in the economic dimension using the formula $\varphi_{j 1}^{1}=\frac{\varphi_{j 11}^{1}+\varphi_{j 12}^{1}}{2}$ in order 1 and $\varphi_{j 2}^{1}=\frac{\varphi_{j 2 t}^{1}}{1}$ in order 2, where $t \epsilon T_{21}$. Moreover, in the environmental dimension, we have

$$
\begin{aligned}
& \varphi_{j 1}^{2}=\frac{\varphi_{j 1 t}^{2}+\varphi_{j 1 t}^{2}+\varphi_{j 1 t}^{2}}{3}, \quad t \in T_{12} \text { for efficiency of order } 1 \\
& \varphi_{j 2}^{2}=\frac{\varphi_{j 2 t}^{2}+\varphi_{j 2 t}^{2}+\varphi_{j 2 t}^{2}}{3}, \quad t \epsilon T_{22} \text { for efficiency of order } 2 \\
& \varphi_{j 3}^{2}=\frac{\varphi_{j 3 t}^{2}}{1}, \quad t \epsilon T_{32} \text { for efficiency of order } 3 .
\end{aligned}
$$

Step 5: For each DMU, we define an overall efficiency score in each dimension, which is the mean efficiency of all orders of efficiency. In the economic dimension, we have

$$
\varphi_{j}^{1}=\frac{\varphi_{j 1}^{1}+\varphi_{j 2}^{1}}{2}
$$

and in the environmental dimension, we have

$$
\varphi_{j}^{2}=\frac{\varphi_{j 1}^{2}+\varphi_{j 2}^{2}+\varphi_{j 3}^{2}}{3} .
$$

Step 6: Finally, having obtained the efficiency scores in all dimensions, we can calculate the overall sustainability efficiency $\left(\varphi_{j}^{\text {sust }}\right)$ through the following formula $\varphi_{j}^{\text {sust }}=\frac{\varphi_{j}^{1}+\varphi_{j}^{2}}{2}$. The value of $\varphi$ would be the solution of Model (3). If $\varphi_{j}^{\text {sust }}=1$, unit $j$ will be efficient, and otherwise, it will be inefficient. The greater the value of $\varphi$ is than one, the higher the level of inefficiency, and the closer it is to one, the lower the level of inefficiency.

To further understand the steps taken in solving the numerical example, Figure 1 presents a step-by-step illustration of the method. In step one, all economically desirable outputs and all environmentally undesirable outputs are taken into consideration. In step two, all possible combinations of desirable outputs $\left(O_{1}\right)$ in the economic dimension and all possible combinations of environmentally undesirable outputs $\left(\mathrm{O}_{2}\right)$ are presented. In step three, using the DEA model, the efficiency score of each decision-making unit is determined for each output combination $t_{k}$ $\left(\varphi_{j k t}^{d}\right)$. In steps four and five, the efficiency of order $j$. And finally, in step six, the overall sustainability efficiency score is calculated for each $D M U_{j}$.

Figure 2 is drawn as an interpretation to Table 2. In this respect, the last column of the table shows the mean economic efficiency scores in different orders of efficiency. Since $\varphi$ is greater than or equal to 1 and there are values higher than 5 in the table, to present the figure 
Table 2: Economic Efficiency of Units Based on Model (1)

\begin{tabular}{|c|c|c|c|c|c|c|}
\hline \multirow{3}{*}{ DMU } & \multicolumn{6}{|c|}{ Sustainability dimensions } \\
\hline & \multicolumn{2}{|c|}{$\begin{array}{l}\text { Economic } \\
\text { dimension } \\
(\text { order } 1)\end{array}$} & \multirow{2}{*}{$\begin{array}{l}\text { Economic } \\
\text { dimension } \\
(\text { order 2) }\end{array}$} & \multirow{2}{*}{$\begin{array}{l}\text { Mean efficiency } \\
\text { of order } 1 \mathrm{in} \\
\text { economic } \\
\text { dimension } \\
\varphi_{j 1}^{1}\end{array}$} & \multirow{2}{*}{$\begin{array}{l}\text { Mean efficiency } \\
\text { of order } 2 \text { in } \\
\text { economic } \\
\text { dimension } \\
\qquad \varphi_{j 2}^{1}\end{array}$} & \multirow{2}{*}{$\begin{array}{l}\text { Mean efficiency } \\
\text { of orders } 1 \& \\
2 \text { in economic } \\
\text { dimension } \\
\varphi_{j}^{1}\end{array}$} \\
\hline & $\varphi_{j 11}^{1}$ & $\varphi_{j 12}^{1}$ & & & & \\
\hline 1 & 3.33 & 12.50 & 3.33 & 7.91 & 3.33 & 5.62 \\
\hline 2 & 3.22 & 11.11 & 3.22 & 7.16 & 3.22 & 5.19 \\
\hline 3 & 1.00 & 1.25 & 1.00 & 1.12 & 1.00 & 1.06 \\
\hline 4 & 2.08 & 1.00 & 1.72 & 1.54 & 1.72 & 1.63 \\
\hline 5 & 2.56 & 2.32 & 2.56 & 2.44 & 2.56 & 2.50 \\
\hline 6 & 1.72 & 1.75 & 1.72 & 1.73 & 1.72 & 1.72 \\
\hline 7 & 1.00 & 1.00 & 1.00 & 1.00 & 1.00 & 1.00 \\
\hline 8 & 1.00 & 1.00 & 1.00 & 1.00 & 1.00 & 1.00 \\
\hline 9 & 3.12 & 5.55 & 3.12 & 4.33 & 3.12 & 3.72 \\
\hline 10 & 3.33 & 11.11 & 1.49 & 7.22 & 1.49 & 4.35 \\
\hline 11 & 1.38 & 1.00 & 1.38 & 1.19 & 1.38 & 1.28 \\
\hline 12 & 1.58 & 7.14 & 1.58 & 4.36 & 1.58 & 2.97 \\
\hline 13 & 2.00 & 11.11 & 2.00 & 6.55 & 2.00 & 4.27 \\
\hline 14 & 1.53 & 1.19 & 1.53 & 1.36 & 1.53 & 1.44 \\
\hline 15 & 1.26 & 1.53 & 1.26 & 1.39 & 1.26 & 1.32 \\
\hline 16 & 1.00 & 1.00 & 1.00 & 1.00 & 1.00 & 1.00 \\
\hline 17 & 3.84 & 2.38 & 3.84 & 3.11 & 3.84 & 3.47 \\
\hline
\end{tabular}


Table 3: Environmental Efficiency of Units Based on Model (3)

\begin{tabular}{|c|c|c|c|c|c|c|c|}
\hline \multirow{2}{*}{ DMU } & \multicolumn{6}{|l|}{\begin{tabular}{l} 
Sustainability dimensions \\
\cline { 2 - 8 }
\end{tabular}} \\
& $\begin{array}{l}\text { Environmental } \\
\text { dimension } \\
\text { (order 1) }\end{array}$ & \multicolumn{3}{l|}{$\begin{array}{l}\text { Environmental } \\
\text { dimension } \\
\text { (order 2) }\end{array}$} & $\begin{array}{l}\text { Environmental } \\
\text { dimension } \\
\text { (order 3) }\end{array}$ \\
\cline { 2 - 8 } & $\varphi_{j 11}^{2}$ & $\varphi_{j 12}^{2}$ & $\varphi_{j 13}^{2}$ & $\varphi_{j 21}^{2}$ & $\varphi_{j 22}^{2}$ & $\varphi_{23}^{2}$ & $\varphi_{j 31}^{2}$ \\
\hline 1 & 1.05 & 1.82 & 1.77 & 1.05 & 1.05 & 1.77 & 1.05 \\
\hline 2 & 3.32 & 3.32 & 3.32 & 3.32 & 3.32 & 3.32 & 3.32 \\
\hline 3 & 1.00 & 1.00 & 1.00 & 1.00 & 1.00 & 1.00 & 1.00 \\
\hline 4 & 1.00 & 1.00 & 1.00 & 1.00 & 1.00 & 1.00 & 1.00 \\
\hline 5 & 2.83 & 2.83 & 2.83 & 2.83 & 2.83 & 2.83 & 2.83 \\
\hline 6 & 1.94 & 1.94 & 1.94 & 1.94 & 1.94 & 1.94 & 1.94 \\
\hline 7 & 1.00 & 1.00 & 1.00 & 1.00 & 1.00 & 1.00 & 1.00 \\
\hline 8 & 1.00 & 1.00 & 1.00 & 1.00 & 1.00 & 1.00 & 1.00 \\
\hline 9 & 3.25 & 3.25 & 3.25 & 3.25 & 3.25 & 3.25 & 3.25 \\
\hline 10 & 1.00 & 1.00 & 1.00 & 1.00 & 1.00 & 1.00 & 1.34 \\
\hline 11 & 1.00 & 1.00 & 1.00 & 1.00 & 1.00 & 1.00 & 1.00 \\
\hline 12 & 1.62 & 1.62 & 1.62 & 1.62 & 1.62 & 1.62 & 1.62 \\
\hline 13 & 1.99 & 1.99 & 1.99 & 1.99 & 1.99 & 1.99 & 1.99 \\
\hline 14 & 1.34 & 1.34 & 1.34 & 1.34 & 1.34 & 1.34 & 1.34 \\
\hline 15 & 1.34 & 1.34 & 1.34 & 1.34 & 1.34 & 1.34 & 1.34 \\
\hline 16 & 1.00 & 1.00 & 1.00 & 1.00 & 1.00 & 1.34 & 1.00 \\
\hline 17 & 4.46 & 4.46 & 4.46 & 4.46 & 4.46 & 4.46 & 4.46 \\
\hline
\end{tabular}


Table 4: Mean Efficiency of Various Orders in the Environmental Dimension

\begin{tabular}{|c|c|c|c|c|}
\hline \multirow{3}{*}{$\mathrm{DMU}$} & \multicolumn{4}{|c|}{ Mean efficiency score } \\
\hline & $\begin{array}{l}\text { Mean } \\
\text { efficiency of } \\
\text { order 1 }\end{array}$ & $\begin{array}{l}\text { Mean } \\
\text { efficiency of } \\
\text { order } 2\end{array}$ & $\begin{array}{l}\text { Mean } \\
\text { efficiency of } \\
\text { order } 3\end{array}$ & $\begin{array}{l}\text { Mean } \\
\text { efficiency of } \\
\text { orders } 1,2, \& 3\end{array}$ \\
\hline & $\varphi_{j 1}^{2}$ & $\varphi_{j 2}^{2}$ & $\varphi_{j 3}^{2}$ & $\varphi_{j}^{2}$ \\
\hline 1 & 1.54 & 1.29 & 1.05 & 1.72 \\
\hline 2 & 3.32 & 3.32 & 3.32 & 3.32 \\
\hline 3 & 1.00 & 1.00 & 1.00 & 1.00 \\
\hline 4 & 1.00 & 1.00 & 1.00 & 1.00 \\
\hline 5 & 2.83 & 2.83 & 2.83 & 2.83 \\
\hline 6 & 1.94 & 1.94 & 1.94 & 1.94 \\
\hline 7 & 1.00 & 1.00 & 1.00 & 1.00 \\
\hline 8 & 1.00 & 1.00 & 1.00 & 1.00 \\
\hline 9 & 3.25 & 3.25 & 3.25 & 3.25 \\
\hline 10 & 1.11 & 1.00 & 1.00 & 1.03 \\
\hline 11 & 1.00 & 1.00 & 1.00 & 1.00 \\
\hline 12 & 1.62 & 1.62 & 1.62 & 1.62 \\
\hline 13 & 1.99 & 1.99 & 1.99 & 1.99 \\
\hline 14 & 1.34 & 1.34 & 1.34 & 1.34 \\
\hline 15 & 1.34 & 1.34 & 1.34 & 1.34 \\
\hline 16 & 1.00 & 1.34 & 1.00 & 1.11 \\
\hline 17 & 4.46 & 4.46 & 4.46 & 4.46 \\
\hline
\end{tabular}


Table 5: Overall Efficiency $\left(\varphi_{\mathbf{j}}^{\text {sust }}\right)$ Obtained Based on the Mean Efficiency Scores in Economic and Environmental Dimensions

\begin{tabular}{|c|c|c|c|c|}
\hline \multirow{3}{*}{ DMU } & \multicolumn{3}{|c|}{ Mean efficiency in economic \& environmental dimensions } & \multirow{3}{*}{$\begin{array}{l}\text { Unit } \\
\text { rankings }\end{array}$} \\
\hline & $\begin{array}{l}\text { Mean efficiency } \\
\text { of orders } 1 \& \\
2 \text { in economic } \\
\text { dimension }\end{array}$ & $\begin{array}{l}\text { Mean efficiency } \\
\text { of orders } 1,2, \& 3 \\
\text { in environmental } \\
\text { dimension }\end{array}$ & $\begin{array}{l}\text { Mean efficiency of all } \\
\text { orders in economic } \\
\& \text { environmental } \\
\text { dimensions }\end{array}$ & \\
\hline & $\varphi_{j}^{1}$ & $\varphi_{j}^{2}$ & $\varphi_{j}^{\text {sust }}$ & \\
\hline 1 & 5.62 & 1.72 & 3.67 & 14 \\
\hline 2 & 5.19 & 3.32 & 4.25 & 16 \\
\hline 3 & 1.06 & 1.00 & 1.03 & 2 \\
\hline 4 & 1.63 & 1.00 & 1.31 & 5 \\
\hline 5 & 2.50 & 2.83 & 2.66 & 10 \\
\hline 6 & 1.72 & 1.94 & 1.83 & 8 \\
\hline 7 & 1.00 & 1.00 & 1.00 & 1 \\
\hline 8 & 1.00 & 1.00 & 1.00 & 1 \\
\hline 9 & 3.72 & 3.25 & 3.48 & 13 \\
\hline 10 & 4.35 & 1.03 & 2.69 & 11 \\
\hline 11 & 1.28 & 1.00 & 1.14 & 4 \\
\hline 12 & 2.97 & 1.62 & 2.29 & 9 \\
\hline 13 & 4.27 & 1.99 & 3.13 & 12 \\
\hline 14 & 1.44 & 1.34 & 1.39 & 7 \\
\hline 15 & 1.32 & 1.34 & 1.33 & 6 \\
\hline 16 & 1.00 & 1.11 & 1.05 & 3 \\
\hline 17 & 3.47 & 4.46 & 3.96 & 15 \\
\hline
\end{tabular}




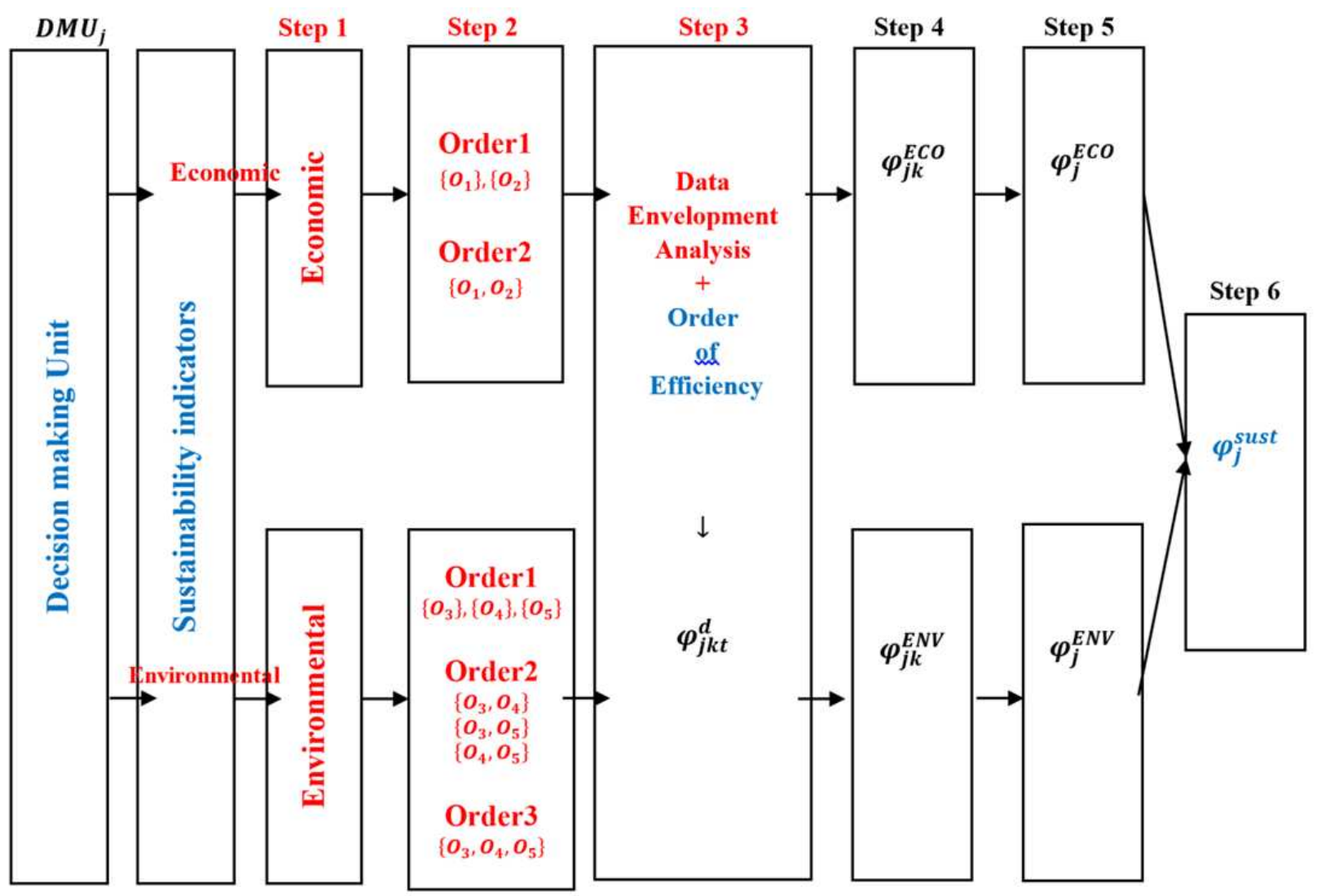

Figure 1: Graphic Representation of the Application of Enhanced DEA in Sustainability Evaluation in Summary

in a more orderly fashion, we use the equation $\theta=\frac{1}{\varphi}$ so that all efficiency values become less than or equal to 1 in terms of $\theta$. As can be observed in Figure 2, units 7, 8, and 16 are on the frontier of 1 and are therefore efficient; these DMUs also have an efficiency score of 1 in the last column of Table 2. First, the environmental efficiency of the units are calculated using Model 3, as presented in Table 3, and then, the orders of efficiency are calculated for the environmental dimension in Table 4 . The last column of Table 4 shows the mean values of the orders of environmental efficiency, based on which Figure 2 is drawn. It should be noted that Figure 3 is adjusted in terms of $\varphi$. Figure 4 illustrates the mean values of economic and environmental efficiency scores in terms of $\varphi$. Figure 5 is a combination of Figures 2, 3, and 4; in this figure, the blue, grey, and red lines represent the mean scores for overall efficiency, economic efficiency, and environmental efficiency, respectively.

To demonstrate the concept of order of efficiency, we refer to Figures 6, 7, and 8, which pertain to the efficiency of order 1 and show the effect of each undesirable output on the problem separately (first three columns of Table 3). In this regard, in order 1, only one undesirable output is taken into account and the other two are disregarded. The red lines in Figure 6 represent the efficiency resulting from the impact of $\mathrm{CO}_{2}$ (first column of Table 3), the blue lines in Figure 7 indicate the efficiency resulting from the effect of SPM (second column of Table 3), and the green lines in Figure 8 show the efficiency resulting from the impact of (third column of Table 3). As can be observed, all three undesirable outputs had a similar impact 


\section{Efficiency in Economic Dimension}

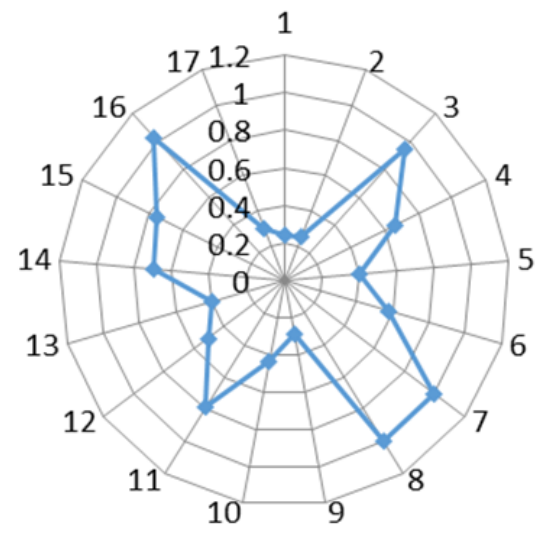

Figure 2: Graphic Representation of Efficiency in the Economic Dimension (Table 2, last column, $\left.\theta=\frac{1}{\varphi_{\mathbf{j}}^{1}}\right)$

\section{Efficiency in Environmental Dimension}

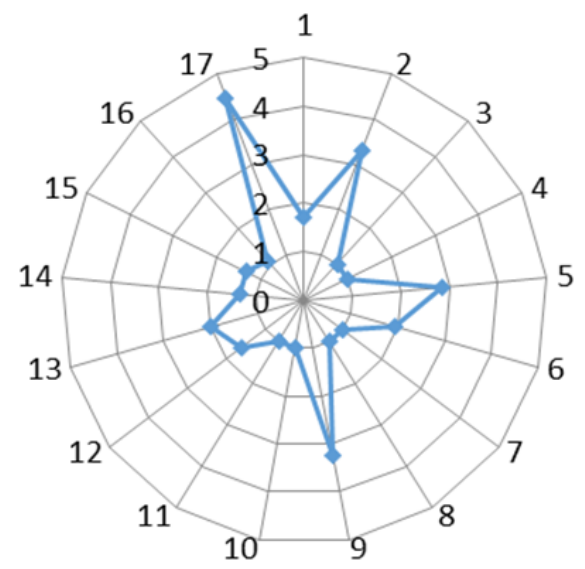

Figure 3: Graphic Representation of Efficiency in the Environmental Dimension(Table 4, last column) 


\section{Efficiency in Environmental Dimension}

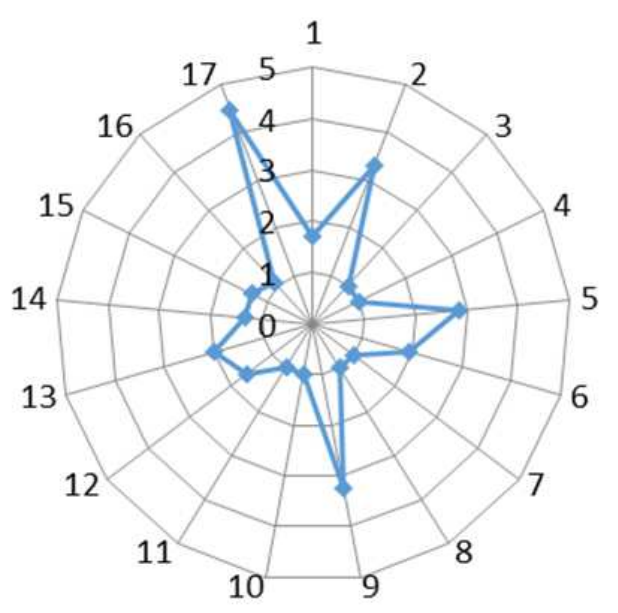

Figure 4: Graphic Representation of Overall Efficiency Scores (Table 5, Third column $\varphi_{\mathbf{j}}^{\text {sust }}$ )

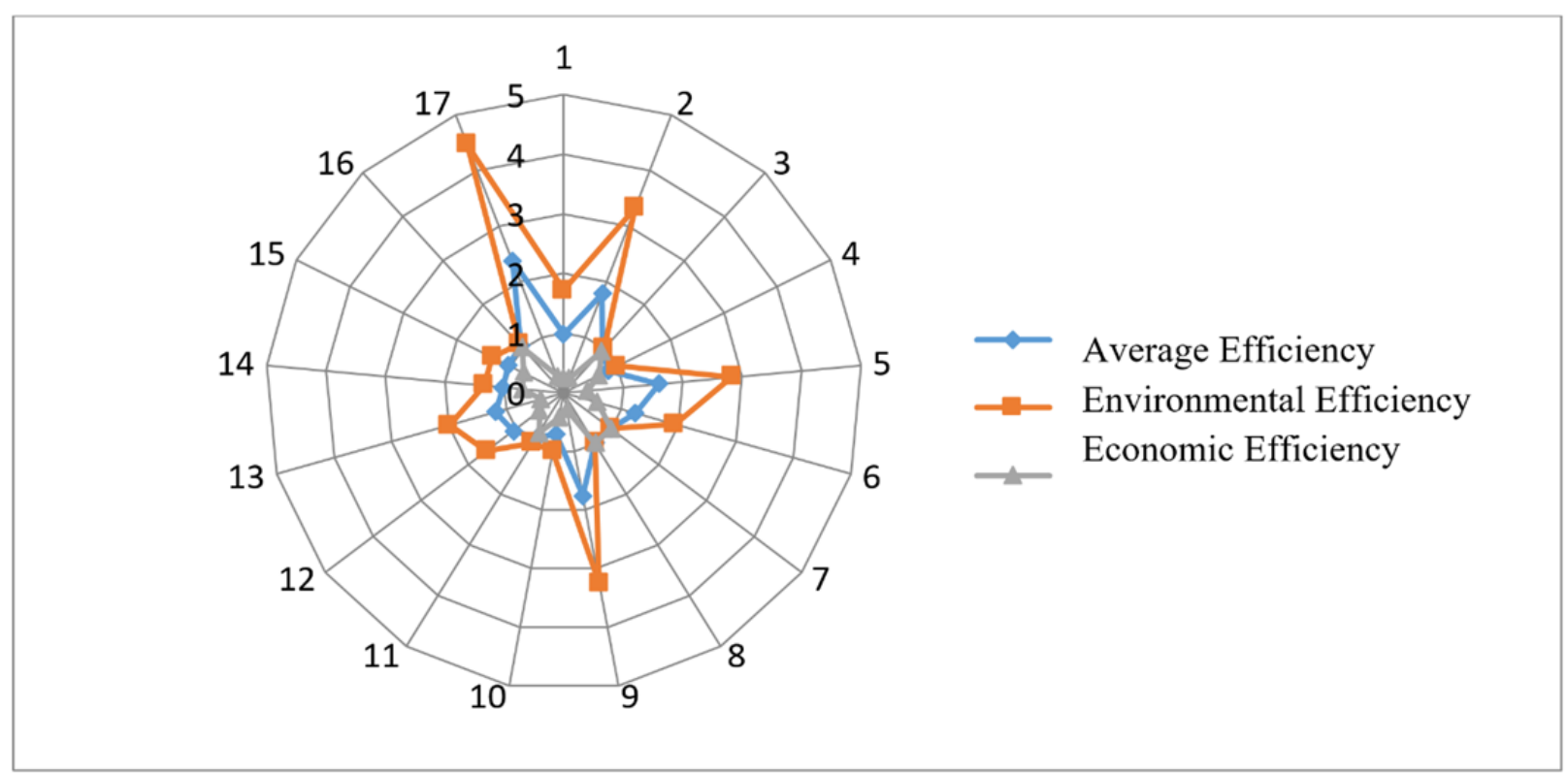

Figure 5: Graphic Representation of Mean Overall Efficiency Scores and Efficiency in the Economic and Environmental Dimensions 
on the efficiency of their respective decision-making units; in this respect, if we consider the red, blue, and green lines simultaneously, we can see that the lines are extremely close to each other and even overlap in many of the DMUs. It is only in $D M U_{1}$ that the frontiers differ, as this DMU is extremely close to the efficiency frontier in Figure 5. In other words, it can be interpreted that the undesirable output $C \mathrm{O}_{2}$ does not cause $D M U_{1}$ to be inefficient, while SPM and $\mathrm{SO}_{2}$ influence the efficiency of unit 1 and make it inefficient.

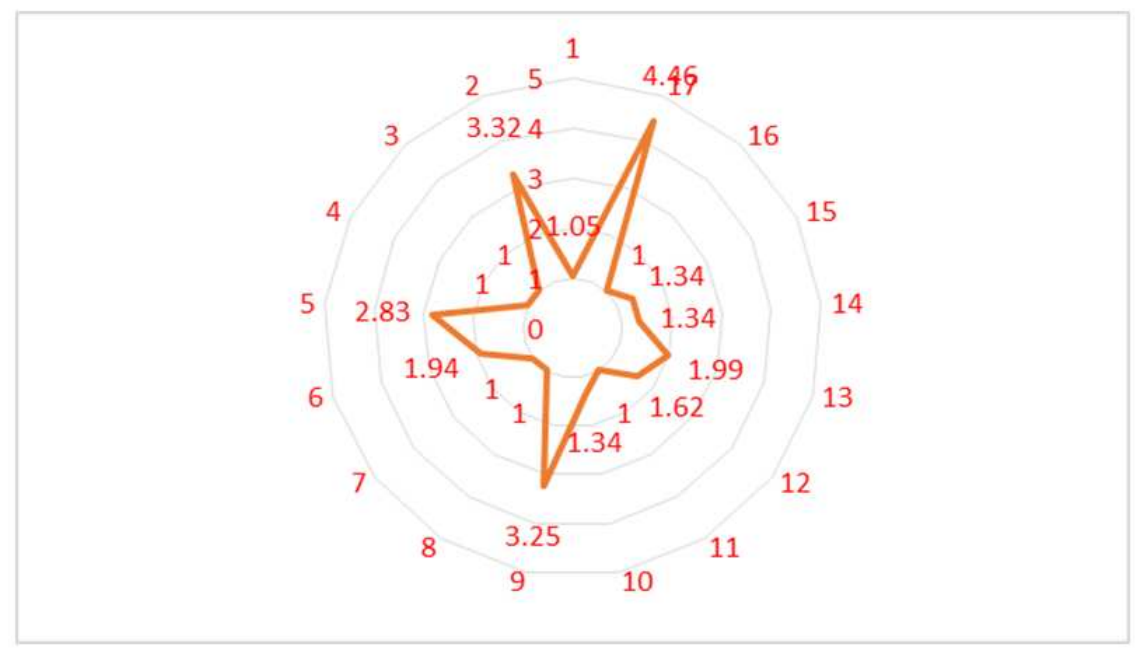

Figure 6: Environmental Efficiency Resulting from the Impact of the Undesirable Outputs $\mathbf{C O}_{2}$ (Table 3, First Column, $\varphi_{j 11}^{2}$ )

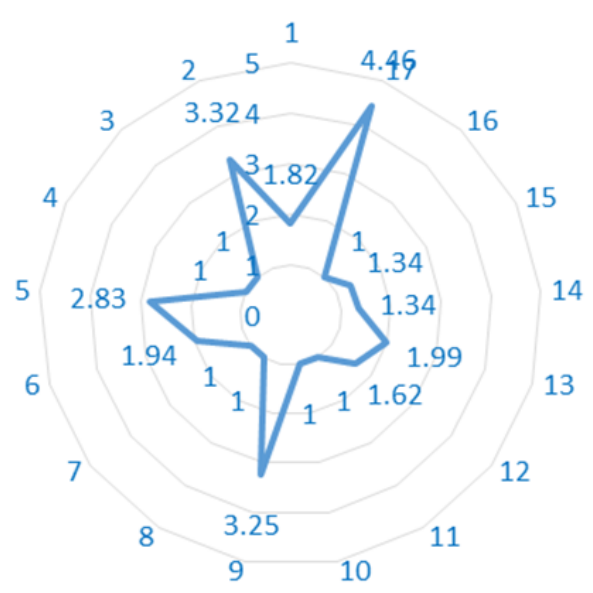

Figure 7: Environmental Efficiency Resulting from the Impact of the Undesirable Outputs $\operatorname{SPM}\left(\right.$ Table 3, Second Column, $\left.\varphi_{j 12}^{2}\right)$

As can be observed in Figure 8, both $D M U_{7}$ and $D M U_{8}$ fall upon a circle with a radius of one, which is defined as the efficiency frontier. The further away a DMU gets from the unit circle, the less efficient it will be. 


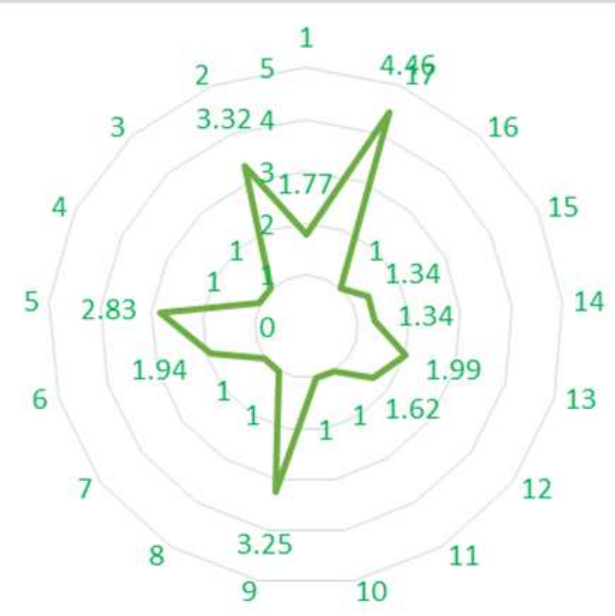

Figure 8: Environmental Efficiency Resulting from the Impact of the Undesirable Outputs $\mathrm{SO}_{2}$ (Table 3, Third Column, $\varphi_{j 13}^{2}$ )

\section{Results and Discussion}

In recent years, all countries have realized the critical importance of attention to the environment alongside economic growth. Consequently, they are after solutions that would allow maximum economic growth with minimum damage to the environment. In this study, the sustainability efficiency of 17 active industries in Iran have been evaluated in the economic and environmental dimensions based on the axiom of strong disposability. The integration of orders of efficiency into the proposed method allows us to identify the most sustainable options among efficient and inefficient units polluting the environment. Our findings reveal that Iranian industries are not in a good condition in terms of environmental efficiency. Thereby, they need to devise and execute certain plans in order to improve their environmental efficiency, so that they can survive and expand their capacity for economic development without harming the environment and endangering the public health. With this viewpoint, considering environmental pollutants as undesirable outputs, the efficiency of active industries in Iran has been evaluated in this study using data envelopment analysis. It should be noted that the input and desirable and undesirable output data extracted for the 17 industries under study, which are provided in Table 1, were calculated as percentages within the same time period. Moreover, the undesirable outputs including $\mathrm{CO}_{2}$, SPM and $\mathrm{SO}_{2}$ were expressed in tons, the employee counts were expressed in million individuals, and value added and import and export turnover were expressed in billion Riyal. The following results were obtained from Model (1) for economic efficiency and Model (3) for environmental efficiency. In Table 2, according to the mean efficiency scores of orders 1 and 2 in the economic dimension $\left(\varphi_{j}^{1}\right)$, which were obtained by solving Model (1), units 7 (coal), 8 (chemicals) and 16 (automotive industry) are the most efficient DMUs and units 1 (food), 2 (textiles and clothing), 9 (plastics), 10 (minerals), 13 (machinery) and 17 (furniture manufacturing) are the most inefficient ones. In the environmental dimension, where the strong disposability model was applied (Table 4 ), based on the mean efficiency scores of orders 1, 2, and 3 obtained from Model $(3)\left(\varphi_{j}^{2}\right)$, 
units 3 (leather), 4 (wood), 7 (coal), 8 (chemicals) and 11 (metals) are found to be the most efficient industries and units 2 (textiles and clothing), 5 (paper), 9 (plastics) and 17 (furniture manufacturing) are recognized as the most inefficient DMUs. Finally, according to Table 5, which presents the mean overall efficiency scores in the environmental and economic dimensions combined $\left(\varphi_{j}^{\text {sust }}\right)$, units 7 (coal) and 8 (chemicals) are considered the most efficient units and unit 2 (textiles and clothing) is identified as the most inefficient one. In addition, according to Table 5, units 7 and 8 had the highest ranks and units 2 and 17 were ranked the lowest, in that order.

\section{Conclusion}

In the present research, using a number of proposed models based on data envelopment analysis, we engaged in a sustainability efficiency evaluation of a number of decision-making units. In the past few decades, the environmental problems caused by the simultaneous production of undesirable products alongside desirable products have been severely overlooked. Furthermore, considering the discussions on sustainable development during recent years, the observed environmental issues not only do not present a positive perspective on the efficiency of economic units but also indicate a total disregard for the environment in their production processes. Recently, the environmental performance of units has gained global support and attracted the attention of environmental policy makers. In line with these changes, the current study, in addition to taking desirable and undesirable data into account, also focuses on orders of efficiency for the first time.

One of the problems in the present research is data collection in different dimensions of efficiency. For example, in many of the existing industries, there has not been any research into the social impact of the industry on people's lives, and their economic and environmental effects on welfare, health, mental security, and job creation in a society are not yet identified (social dimension). For this reason, in the efficiency evaluation of industries, we took the economic and environmental dimensions into consideration, while being forced to eliminate the social dimension.

In addition, the existing environmental literature only focused on air pollution, while the amount of harmful industrial waste in the soil, the industrial contamination of rivers and seas, and noise pollution levels are disregarded. The fact is that such extensive research would require a government grant, as well as the cooperation of all organizations and industries, which is not a possibility in the current research due to our limited budget and authority.

For future research, we recommend studying all dimensions of a case study for efficiency evaluation. For example, we can first determine the social indicators and priorities of each industry using the analytic hierarchy process (AHP) or the balanced score card (BSC), and then convert the qualitative priorities into quantitative ones through the abovementioned methods or similar approaches and apply them in the social dimension. Furthermore, if we can design an extensive national project with the cooperation of all industries, we will be able to more accurately determine the amount of pollution each industry is causing in the water and the soil and add them to the undesirable outputs as other types of environmental pollution. 


\section{References}

[1] Luthy, R. G., Bella, D. A., Hunt, J. R., Johnson Jr, J. H., Lawler, D. F., O'Melia, C. R. and Pohland, F. G. Future concerns in environmental engineering graduate education. professional issues in engineering education and practice. 1992. 118 (4): 361-380.

[2] Gilman-Robert. Sustainability. 1996. URL: www.context.org/ICIB/DEFS/AIADef.html.

[3] Zahedi, S. and Najafi, G. Conceptual expansion of sustainable development. Human Sciences Modares. 2006. 10(4): 43-76.

[4] Dabiri, F., Khalatbari, Y. Achieving sustainable development from the perspective of international environmental law. Human \& Environment Quarterly. 2018. 16: 63-73.

[5] Azadbakht, B. Analysis of the Place of Environment in the Macro Policies and Planning Laws of Iran Since the Formation of the 5-year Development Plans and Longterm Environmental Protection Policies. Master's Thesis in Environmental Law, Azad University, Science and Research Branch. 2005.

[6] Pope, J., Annandale, D. and Morrison-Saunders, A. Conceptualising sustainability assessment. Environmental Impact Assessment Review. 2004. 24(6): pp.595-616.

[7] Grossmann, I. E. and Guillén-Gosálbez, G. Scope for the application of mathematical programming techniques in the synthesis and planning of sustainable processes. Computers \&3 Chemical Engineering. 2010. 34(9): 1365-1376.

[8] Charnes, A., Cooper, W. W. and Rhodes, E., Measuring the efficiency of decision making units. European Journal of Operational Research. 1978. 2(6): 429-444.

[9] Pittman R.W. Multilateral productivity comparisons with undesirable outputs. The Economic Journal. 1983. 93(372): 883-891.

[10] Färe, R., Grosskopf, S., Lovell, C. A. K. and Pasurka, C. Multilateral productivity comparisons when some outputs are undesirable: a nonparametric approach. The Review of Economics and Statistics. 1989. 7(1): 90-98.

[11] Hoang, V. N. and Alauddin, M. Input-orientated data envelopment analysis framework for measuring and decomposing economic, environmental and ecological efficiency: an application to OECD agriculture. Environmental and Resource Economics. 2012. 51(3): 431-452.

[12] Chen, L. and Jia, G. Environmental efficiency analysis of China's regional industry: a data envelopment analysis (DEA) based approach. Journal of Cleaner Production. 2017. 142: 846-853.

[13] Liu, J., Liu. H., Yao, X. L. and Liu, Y. Evaluating the sustainability impact of consolidation policy in China's coal mining industry: a data envelopment analysis. Journal of Cleaner Production. 2016. 112. 2969-2976.

[14] Zhou, P., Poh, K. L. and Ang, B. W. Data envelopment analysis for measuring environmental performance. In Handbook of Operations Analytics using Data Envelopment Analysis. 31-49. Springer, Boston, M A. 2016.

[15] Chen, L., Wang, Y. M. and Lai, F. Semi-disposability of undesirable outputs in data envelopment analysis for environmental assessments. European Journal of Operational Research. 2017. 260(2): 655-664. 
[16] Xie, B. C., Duan, N. and Wang, Y. S. Environmental efficiency and abatement cost of China's industrial sectors based on a three-stage data envelopment analysis. Journal of cleaner production. 2017. 153: 626-636.

[17] Yang, W. and Li, L. Efficiency evaluation of industrial waste gas control in China: A study based on data envelopment analysis (DEA) model. Journal of cleaner production. 2018. 179: $1-11$.

[18] Chang, D. S., Kuo, L. C. R. and Chen, Y. T. Industrial changes in corporate sustainability performance-an empirical overview using data envelopment analysis. Journal of Cleaner production. 2013. 56: 147-155.

[19] Khodakarami, M., Shabani, A. and Saen, R. F. A new look at measuring sustainability of industrial parks: a two-stage data envelopment analysis approach. Clean Technologies and Environmental Policy 2014. 16(8): 1577-1596.

[20] Reig-Martínez, E., Gómez-Limón, J. A. and Picazo-Tadeo, A. J. Ranking farms with a composite indicator of sustainability. Agricultural economics. 2011. 42(5): 561-575.

[21] Tajbakhsh, A. and Hassini, E. A data envelopment analysis approach to evaluate sustainability in supply chain networks. 2014. J. Clean Prod. htpp://lldx.doi.org/ 110. 1016lj. jclepro.2014.07.054.

[22] Galán-Martín, Á., Guillén-Gosálbez, G., Stamford, L. and Azapagic, A. Enhanced data envelopment analysis for sustainability assessment. In Computer Aided Chemical Engineering. 2016. 38: 817-822. Elsevier.

[23] Adler, N., Friedman, L. and Sinuany-Stern, Z. Review of ranking methods in the data envelopment analysis context. European Journal of Operational Research. 2002. 140(2): 249-265.

[24] Lotfi, F. H., Jahanshahloo, G. R., Khodabakhshi, M., Rostamy-Malkhlifeh, M., Moghaddas, Z. and Vaez-Ghasemi, M. A review of ranking models in data envelopment analysis. Journal of Applied Mathematics. ID492421(20 pages). https://doi.org/101155/2013/492421.

[25] Washio, S. and Yamada, S. Evaluation method based on ranking in data envelopment analysis. Expert Systems with Applications. 2013. 40(1): 257-262.

[26] Wu, J., Sun, J. and Liang, L. Cross efficiency evaluation method based on weight-balanced data envelopment analysis model. Computers $\&$ Industrial Engineering. 2012. 63(2): 513519.

[27] Zerafat Angiz, M., Mustafa, A., Kamali, M. J. Cross-ranking of decision making units in data envelopment analysis. Appl. Math. Model. 2013. 37: 398-405.

[28] Chen, Y., Du, J. and Huo, J. Super-efficiency based on a modified directional distance function. Omega. 2013. 41(3): 621-625.

[29] Li, S., Jahanshahloo, G.R. and Khodabakhshi, M. A super-efficiency model for ranking efficient units in data envelopment analysis. Applied Mathematics and Computation. 2007. 184(2): 638-648.

[30] Jahanshahloo, G. R., Memariani, A., Lotfi, F. H., Rezai, H. Z. A note on some of DEA models and finding efficiency and complete ranking using common set of weights. Appl. Math. Comput. 2005. 166, 265-281. 
[31] Wang, Y. M., Luo, Y. and Lan, Y. X. Common weights for fully ranking decision making units by regression analysis. Expert Systems with Applications. 2011. 38(8): 9122-9128.

[32] Chen, J.X., Deng, M. and Gingras, S. A modified super-efficiency measure based on simultaneous input-output projection in data envelopment analysis. Computers 83 Operations Research. 2011. 38(2): 496-504.

[33] Lu, W. M. and Lo, S. F. An interactive benchmark model ranking performers - application to financial holding companies. Mathematical and Computer Modelling. 2009. 49(1-2): 172179.

[34] Hosseinzadeh-Lotfi, F., Rostamy-Malkhalifeh, M., Aghayi, N., Ghelej Beigi, Z., Gholami, $\mathrm{K}$. An improved method for ranking alternatives in multiple criteria decision analysis. Appl. Math. Model. 2013. 37: 25-33.

[35] Jablonsky, J. Multicriteria approaches for ranking of efficient units in DEA models. Cent. Eur. J. Oper. Res. 2011. 20 : 435-449. http://dx.doi.org/10.1007/s10100-011-0223-6.

[36] Färe, R., Grosskopf, S. New Direction: Efficiency and Production. Springer, Essay. 45-65. 2003.

[37] Shephard, R. W. and Färe, R.. The law of diminishing returns. In Production theory (pp. 287-318). Springer, Berlin, Heidelberg. 1974.

[38] Färe, R., Grosskopf, S., Noh, D.W. and Weber, W. Characteristics of a polluting technology: theory and practice. Journal of Econometrics. 2005. 126(2): 469-492.

[39] Lawrence, M., Seiford, A. and Zhu, J. Modeling undesirable factors in efficiency evaluation. European Journal of Operational Research. 2002. 142: 16-20.

[40] Fare, R. and Grosskopf, S. Non-parametric productivity analysis with undesirable outputs: Comment. American Journal of Agricultural Economics. 2003. 85: 1070-1074.

[41] Hailu, A. and Veeman, T. S. Non-parametric productivity analysis with undesirable outputs: an application to the canadian pulp and paper industry. American Journal of Agricultural Economics . 2001. 83: 605-16.

[42] Lozano, S., Gutierrez, E. and Moreno, P. Network DEA approach to airports performance assessment considering undesirable outputs. Applied Mathematical Modelling. 2013. 37: $1665-1676$.

[43] Das, I., A preference ordering among various Pareto optimal alternatives. Structural optimization. 1999. 18(1): 30-35.

[44] Nasrolahi, Z. and Talei Ardakani, S. Estimating Shadow Economy and the Impact on Air Pollution in Iran. The Economic Research. 2013. 12(4): 27-54. 